\title{
Erratum to: Impact of impoundment on groundwater seepage in the Three Gorges Dam in China based on CFCs and stable isotopes
}

\author{
Lei Zhang $\cdot$ Duoxing Yang $\cdot$ Yaowei Liu $\cdot$ \\ Yongtai Che $\cdot$ Dajun Qin
}

Published online: 2 July 2014

(c) Springer-Verlag Berlin Heidelberg 2014

\section{Erratum to: Environ Earth Sci \\ DOI 10.1007/s12665-014-3349-8}

The authors would like to correct errors in the original publication as detailed below.

Under the heading 'Methods' the sentence "average air temperature of the study area" should read as "average recharge temperature".

In the sub-heading, $\mathrm{CFC}$ data of the 'Results' section, the values of CFC-11 (3.0-7.62) and CFC-12 (1.63-2.46) should read as "CFC-11 (3.0-5.9)", and "CFC-12 (1.48-2.46)", respectively.

The online version of the original article can be found under doi:10.1007/s12665-014-3349-8.

\section{Zhang}

Institute of Geophysics, China Earthquake Administration,

Beijing 100081, China

L. Zhang $\cdot$ D. Yang $(\bowtie) \cdot$ Y. Liu $(\bowtie)$

Key Laboratory of Crustal Dynamics,

Institute of Crustal Dynamics, China Earthquake Administration,

Beijing 100085, China

e-mail: yangdx@mail.iggcas.ac.cn

Y. Liu

e-mail: liuyw20080512@163.com; liuyw20080512@126.com

\section{Y. Che}

Institute of Geology, China Earthquake Administration,

Beijing 100029, China

D. Qin

Key Laboratory of Engineering Geomechanics, Institute of Geology and Geophysics,

Chinese Academy of Sciences, Beijing 100029, China
In Table 2, the headings "2009-2008", "2010-2015", and "2010-2010" should read as "2009.08", "2010.05" and "2010.10", respectively.

In the "Conclusions" section, the sentence "However, the data for well W7 suggest that there is diffusion of the pore pressure in the central section of the X.F. during the impoundment." should be deleted. 